Pesq. Vet. Bras. 29(5):382-386, maio 2009

\title{
Enterite granulomatosa associada a larvas de ciatostomíneos em eqüinos no Rio Grande do Sul ${ }^{1}$
}

\author{
Felipe Pierezan², Daniel R. Rissi², José C. Oliveira Filho², Ricardo B. Lucena², \\ Camila Tochetto ${ }^{3}$, Mariana M. Flores ${ }^{3}$, Fábio B. Rosa ${ }^{3}$ e Claudio S.L. Barros ${ }^{4 *}$
}

ABSTRACT.- Pierezan F., Rissi D.R., Oliveira Filho J.C., Lucena R.B., Tochetto C., Flores M.M., Rosa F.B \& Barros C.S.L. 2009. [Granulomatous enteritis associated with larval cyathostomiasis in horses in Rio Grande do Sul, Brazil.] Enterite granulomatosa associada a larvas de ciatostomíneos em eqüinos no Rio Grande do Sul. Pesquisa Veterinária Brasileira 29(5):382-386. Departamento de Patologia, Universidade Federal de Santa Maria, 97105-900 Santa Maria, RS, Brazil. E-mail: claudioslbarros@uol.com.br

Five cases of granulomatous enteritis associated with cyathostomes are described in horses from three farms in Rio Grande do Sul, Brazil. The cases occurred from January 1999 to December 2007. The clinical course in two cases in which clinical follow-up was available was 10-14 days. Clinical signs presented by two horses were similar and included diarrhea (3/3), weight loss (2/3), pyrexia (1/3), tachycardia (1/3), and tachypnea (1/3). Gross changes consisted of thickening of the wall of large colon and cecum by edema and the occurrence of numerous $1-4 \mathrm{~mm}$, dark-tan, slightly raised multifocal pinpoints disseminated throughout the mucosa. Up on the incision of these pinpoints, brown-reddish, small $(1-2 \mathrm{~mm})$ nematode larvae emerged. Large numbers of parasites with morphology compatible with small strongyles were observed in the lumina of large colon and cecum or adhered to the mucosae of these organs. Histologically, multiple granulomas were seen in the mucosa and submucosa of large colon and cecum. These granulomas consisted of moderate to severe inflammatory infiltrate of macrophages, epithelioid macrophages, and eosinophils surrounded by fewer lymphocytes and plasma cells. In the center of these granulomas, transversal cut sections of parasites with morphology compatible with cyathostomes larvae were observed. Additionally, there was edema and moderate to marked lymphohistioplasmacytic and eosinophilic inflammatory infiltrate throughout the mucosa and submucosa of the large colon and cecum; necrosis and lymphohistiocytic proliferation in the submucosal lymphoid follicles, with hyperplasia of goblet cells in the epithelial lining of these organs were also observed. The diagnosis of granulomatous enteritis associated with larval cyathostomiasis was made based on epidemiological, clinical, and gross findings which were confirmed by histopathology.

INDEX TERMS: Diseases of horses, small strongylus, diseases of the digestive system, cyathostomes, pathology.

\footnotetext{
${ }^{1}$ Recebido em 8 de dezembro de 2008.

Aceito para publicação em 15 de dezembro de 2008.

Parte da Dissertação de Mestrado do primeiro autor.

2 Programa de Pós-graduação em Medicina Veterinária, área de concentração em Patologia Veterinária, Centro de Ciências Rurais, Universidade Federal de Santa Maria (UFSM).

${ }^{3}$ Bolsista de Iniciação científica do CNPq junto ao Departamento de Patologia da UFSM.

${ }^{4}$ Departamento de Patologia, UFSM, Santa Maria, RS 97105-900. *Pesquisador 1A CNPq. *Autor para correspondência: claudioslbarros@uol.com.br
}

RESUMO.- São descritos cinco casos de enterite granulomatosa associada a larvas de ciatostomíneos em eqüinos provenientes de três propriedades rurais do Rio Grande do Sul. Os casos ocorreram entre janeiro de 1999 e dezembro de 2007. A evolução clínica nos dois casos cujo seguimento clínico foi acompanhado foi de 10 e 14 dias. Os sinais clínicos apresentados por três eqüinos foram semelhantes e consistiam de diarréia (3/3), emagrecimento $(2 / 3)$, pirexia $(1 / 3)$, taquicardia $(1 / 3)$ e taquipnéia $(1 / 3)$. Os achados macroscópicos incluíram espessamento da 
parede do cólon maior e ceco por edema e ocorrência de numerosos pontos marrom-escuros com 1-4mm, levemente salientes, disseminados pela mucosa. A incisão desses pontos revelou pequenas larvas de nematódeos marrom-avermelhadas de 1-2mm. Numerosos parasitas, compatíveis morfologicamente com pequenos estrôngilos, foram observados na luz intestinal ou aderidos à mucosa do cólon maior e ceco. Histologicamente, na mucosa e submucosa do cólon maior e ceco, foram observados múltiplos granulomas constituídos por moderado ou acentuado infiltrado inflamatório, composto por macrófagos, macrófagos epitelióides e eosinófilos circundados por linfócitos e plasmócitos. No centro desses granulomas, observaram-se cortes transversais de parasitas com morfologia compatível com ciatostomíneos. Adicionalmente, havia edema e infiltrado inflamatório linfo-histioplasmocitário e eosinofílico, leve ou moderado na submucosa e mucosa do cólon maior e ceco; necrose e proliferação linfo-histiocítária em folículos linfóides na submucosa e hiperplasia de células caliciformes na mucosa. O diagnóstico de enterite granulomatosa associada a ciatostomíneos foi realizado com base nos achados epidemiológicos, clínicos e macroscópicos e confirmado pela histologia.

TERMOS DE INDEXAÇÃO: Doenças de eqüinos, pequenos estrôngilos, doenças do sistema digestivo, ciastotomíneos, patologia.

\section{INTRODUÇÃO}

Nos últimos anos, os ciatostomíneos passaram a ter importância na medicina interna de eqüinos devido ao aumento de sua incidência e à ocorrência de casos de diarréia e mortes associadas à infestação por esses parasitas. Surtos e casos isolados de diarréia associada à lesão provocada por ciatostomíneos têm sido descritos em todo mundo (Jasko \& Roth 1984, Giles et al. 1985, Harmon et al. 1986, Reilly et al. 1993, Mair 1994) e no Brasil (Schild et al. 1989, Rech et al. 2001).

Há mais de 40 espécies identificadas desses parasitas, popularmente conhecidos como triconemas, ciatostomíneos ou pequenos estrôngilos. Essas espécies fazem parte dos gêneros Cylicosephanus, Cyathostomum, Cylicocyclus, Cylicodontophorus, Poeriostomum, Gyalocephalus e Cylindropharynx (Urquhart et al. 1996). As dez espécies mais comuns em eqüinos são Cylicosephanus longibursatus, Cyathostomum catinatum, Cylicosephanus goldi, Cylicocyclus nassatus, Cyathostomum coronatum, Cylicosephanus calicatus, Cylicosephanus minutus, Cylicocyclus leptosomus, Cyathostomum pateratum e Cylicocyclus insigne (Lyons et al. 2000). São parasitas pequenos $(<1,5 \mathrm{~cm}$ de comprimento), filiformes, brancos ou vermelho-escuros, visíveis no exame minucioso da mucosa ou no conteúdo do intestino grosso de eqüinos (Urquhart et al. 1996). A diferenciação entre as espécies é feita (1) pela observação do número, arranjo, forma e tamanho dos elementos das coroas lamelares interna e externa, (2) forma da cápsula bucal, incluindo suas pare- des, e (3) pela forma e tamanho da cauda em machos e sua configuração em fêmeas (Lyons et al. 2000).

Esses parasitas têm seis estágios de vida em ciclo direto (i.é., não possuem hospedeiros intermediários), que incluem: ovos, larvas de primeiro estágio $\left(L_{1}\right)$, larvas de segundo estágio $\left(L_{2}\right)$, larvas de terceiro estágio $\left(L_{3}\right)$, larvas de quarto estágio $\left(L_{4}\right)$, larvas de quinto estágio $\left(L_{5}\right)$ e adultos. Os parasitas adultos vivem no lúmen intestinal, onde produzem ovos que são eliminados nas fezes. Em condições favoráveis, os ovos eclodem no meio ambiente, onde o parasita se desenvolve de $L_{1}$ a $L_{3}$. As formas infectantes $\left(L_{3}\right)$ são ingeridas com o alimento. No tubo digestivo, principalmente do cólon maior e ceco, essas larvas atravessam o epitélio intestinal e penetram a lâmina própria e submucosa. Nesses locais, desenvolvem-se em $\mathrm{L}_{4}$ e emergem para o lúmen em sua forma madura. As larvas remanescentes na parede intestinal formam cistos e entram em hipobiose, onde podem permanecer por até dois anos. Embora casos de diarréia ocorram na maioria das vezes associados à emergência de larvas encistadas nas paredes do intestino, essa síndrome também pode ser provocada pela penetração da $L_{3}$ (Giles et al. 1985, Lyons et al. 2000).

A doença tem caráter sazonal, porém, há diferença da época de ocorrência nas diferentes regiões do mundo. Dessa forma, as condições mais favoráveis nos países do norte, com clima temperado, ocorrem na primavera e outono, enquanto nos países de clima subtropical, essas condições ocorrem durante o inverno (Lyons et al. 2000).

Os sinais clínicos caracterizam-se por diarréia de início súbito, que pode tornar-se crônica e causar emaciação e morte em 2-3 semanas. Sinais clínicos adicionais incluem cólica, edema subcutâneo e pirexia (Love et al. 1999, Lyons et al. 2000). Não são observadas alterações específicas nos exames hematológicos e bioquímicos, embora a maioria dos eqüinos afetados desenvolva neutrofilia e hipoalbubinemia (Giles et al. 1985).

As lesões intestinais incluem enterite catarral ou fibrinosa no cólon maior e ceco, com numerosos focos de hemorragia, necrose ou formação de granulomas na mucosa e submucosa. Essas lesões são associadas a larvas de ciatostomíneos (Jasko \& Roth 1984, Love et al. 1999, AFIP 2000). Outras lesões intestinais incluem edema da parede intestinal e aumento de volume dos linfonodos mesentéricos (Love et al. 1999).

Apesar de ser uma doença comum de eqüinos em várias regiões do mundo, poucos são os casos de enterite associada à ciatostomíneos descritos no Brasil. O objetivo deste trabalho foi descrever a epidemiologia, os sinais clínicos e os achados de necropsia e histológicos de cinco casos fatais de enterite associada à ciatostomíneos em eqüinos no Rio Grande do Sul.

\section{MATERIAL E MÉTODOS}

Os protocolos de necropsia de eqüinos realizadas no Laboratório de Patologia Veterinária (LPV) da Universidade Federal de Santa Maria (UFSM), no período de janeiro de 1968 a novembro 
de 2007, foram revisados em busca de casos de enterite associada a ciatostomíneos. Nos protocolos dos cinco casos encontrados foram coletadas informações referentes à idade, à época de ocorrência, aos sinais clínicos e às alterações patológicas. Os casos foram identificados por números de 1-5, de acordo com ordem cronológica de ocorrência. Fragmentos de vários órgãos fixados em blocos de parafina foram processados e corados pela técnica de hematoxilina-eosina (HE) para a descrição detalhada do parasita e das lesões histológicas.

\section{RESULTADOS}

No período avaliado foram necropsiados 335 eqüinos no LPV-UFSM, dos quais $13(3,8 \%)$ apresentaram enterite como causa de morte. Desses, cinco $(1,5 \%)$ tiveram diagnóstico de enterite associada a ciatostomíneos. Os dados epidemiológicos dos cinco casos estão resumidos no Quadro 1. Os sinais clínicos eram semelhantes nos Eqüinos 1-3 e incluíam, em ordem decrescente de freqüência, diarréia $(3 / 3)$, emagrecimento $(2 / 3)$, pirexia (1/ $3)$, taquicardia (1/3) e taquipnéia (1/3). A evolução clínica nos Eqüinos 1-2 foi de 14 e 10 dias, respectivamente. Os Eqüinos 4 e 5 foram encontrados mortos no campo.

Os achados macroscópicos eram caracterizados por espessamento da parede do cólon maior e ceco, devido ao edema, e numerosos pontos marrom-escuros, multifocais, com 1-5mm, levemente salientes, na mucosa desses órgãos (Fig.1). A incisão desses pontos revelava

Quadro 1. Dados epidemiológicos de cinco casos de enterite associada à ciatostomíneos em eqüinos no Rio Grande do Sul

\begin{tabular}{cccccc}
\hline Caso & Município & Idade & Raça & Sexo & Data da necrópsia \\
\hline 1 & Santa Maria & 18 anos & $\mathrm{NI}^{\mathrm{a}}$ & $\mathrm{F}^{\mathrm{b}}$ & $13 / 05 / 1999$ \\
$2^{\mathrm{C}^{*}}$ & Santa Maria & 18 meses & Mista & $\mathrm{F}$ & $07 / 08 / 2001$ \\
$3^{* *}$ & São Sepé & 8 meses & Crioulo & $\mathrm{M}^{\mathrm{d}}$ & $23 / 06 / 2005$ \\
$4^{* *}$ & São Sepé & 8 meses & Crioulo & $\mathrm{F}$ & $16 / 08 / 2005$ \\
$5^{*}$ & Santa Maria & 1 ano & Mista & $\mathrm{F}$ & $11 / 05 / 2007$
\end{tabular}

a Não informado; ${ }^{b}$ fêmea; ${ }^{c}$ um resumo deste caso foi apresentado em congresso (Rech et al. 2003); ${ }^{d}$ macho; ${ }^{*} e{ }^{* *}$ pertencentes a uma mesma propriedade.

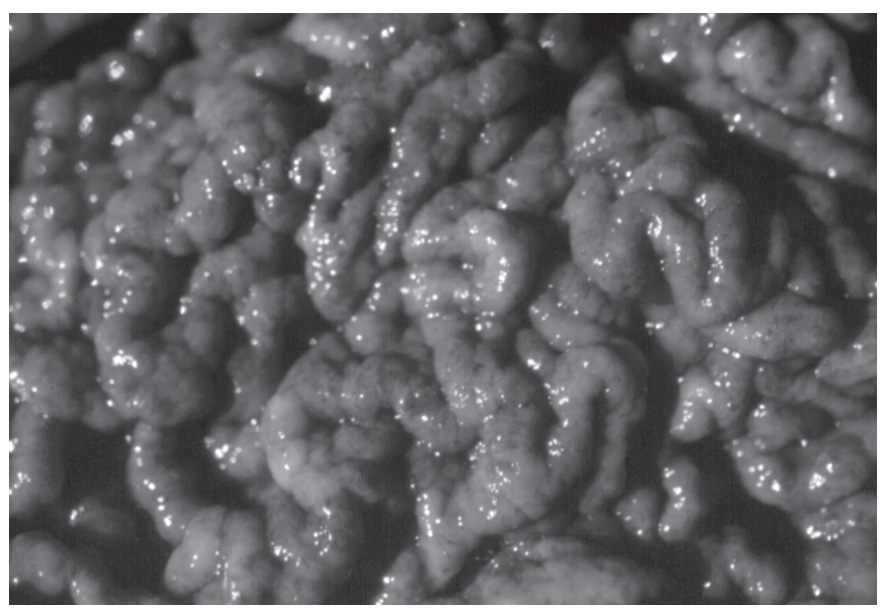

Fig.1. Edema e avermelhamento da parede do cólon maior, com numerosos pontos marrom-escuros com 1-4mm de diâmetro, levemente salientes, disseminados pela mucosa (Eqüino 2). pequenas larvas marrom-avermelhadas com 1-2mm de comprimento. No cólon maior e ceco, em meio ao conteúdo intestinal ou aderidos à mucosa, observavam-se miríades de estruturas filiformes, brancas ou vermelhoescuras, com $0,5-1,0 \mathrm{~cm}$ de comprimento, compatíveis morfologicamente com pequenos estrôngilos. Adicionalmente, foram observados na luz intestinal, exemplares de Anaplocephala sp. (Eqüinos 3 e 5) Strongylus sp., Paranaplocephala sp. e Gasterophilus nasalis (Eqüino 1). Outros achados de necropsia não relacionados com a morte dos eqüinos incluíam arterite da arteria mesentérica cranial associada a larvas de Strongylus vulgaris (Eqüino 1 e 2), nódulos de migração parasitária no fígado (Eqüino 1) e na parede abdominal (Eqüino 3), Hemomelasma ilei na serosa do íleo (Eqüino 1), úlceras gástricas (Eqüino 2) e lipomas pedunculados aderidos ao mesentério (Eqüino 1).

Histologicamente, na mucosa e submucosa do cólon maior e ceco, eram observados múltiplos granulomas constituídos por infiltrado inflamatório moderado ou acentuado, formado por macrófagos, macrófagos epitelióides e eosinófilos, circundados por linfócitos e plasmócitos. No centro desses granulomas eram observadas seções transversais e longitudinais de larvas de metazoários celoma-

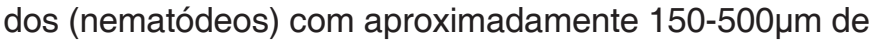
diâmetro (Fig.2). Os parasitas maiores $\left(\mathrm{L}_{4}\right.$ de ciatostomí-

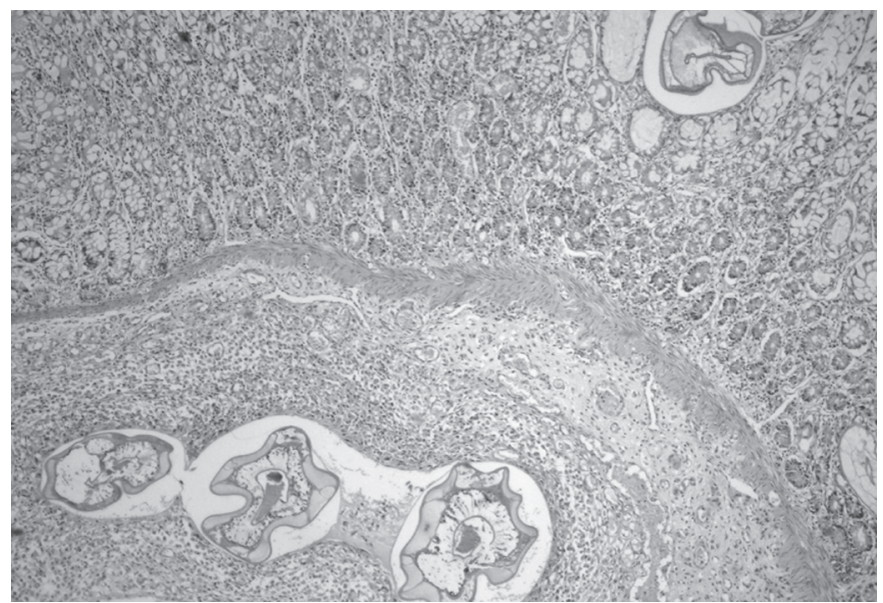

Fig.2. Seções tranversais de nematódeos, com morfologia compatível com ciatostomíneos encistados na submucosa e mucosa do cólon maior (Eqüino 2). Circundando os parasitas na submucosa há intensa reação inflamatória constituída por macrófagos, macrófagos epitelióides e eosinófilos, circundados por linfócitos e plasmócitos. HE, obj.10x.

neos) eram revestidos por uma espessa cutícula eosinofílica. Sob a cutícula era observada musculatura platimiariana/meromiariana, proeminentes cristas cuticulares internas e cordões laterais finamente vacuolizados. $O$ intestino era composto por células grandes com microvilosidades no pólo apical (borda em escova) (Fig.3). Os parasitas menores $\left(\mathrm{L}_{3}\right.$ de ciatostomíneos) caracterizavamse por cutícula espessa e um tubo digestivo grande e revestido por células basofílicas cuboidais (Gardiner \& 


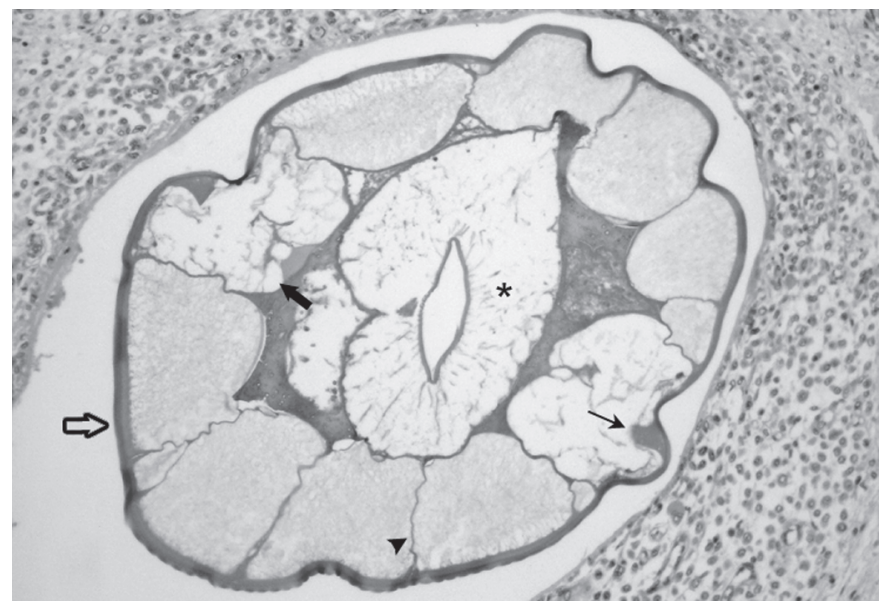

Fig.3. Larva L4 de ciatostomíneos, caracterizada por espessa cutícula eosinofílica (seta vazada), musculatura platimiariana/meromiariana (cabeça de seta), proeminentes cristas cuticulares internas (seta estreita), cordões laterais finamente vacuolizados (seta espessa) e intestino (asterisco) composto por células grandes com microvilosidades no pólo apical (borda em escova), em cólon maior (Eqüino 3). HE, obj.20x.

Poynton 2006). Na submucosa e lâmina própria da mucosa observava-se infiltrado inflamatório moderado, distribuído aleatoriamente pelo parênquima e constituído por macrófagos, linfócitos, plasmócitos e eosinófilos (Fig.2). Em algumas áreas havia ruptura da muscular da mucosa; na submucosa, adjacente a essas áreas de ruptura, havia focos de infiltrado inflamatório constituído predominantemente por macrófagos e linfócitos. A quantidade de eosinófilos nos granulomas ou distribuídos aleatoriamente na lâmina própria e submucosa era variável, e foi mais acentuada nos Eqüinos 4 e 5. Havia espessamento variável da submucosa por edema, caracterizado por separação dos feixes de colágeno, dilatação dos vasos linfáticos (ectasia de linfáticos) e tumefação das células endoteliais dos vasos sangüineos. Em alguns folículos linfóides da submucosa verificavam-se necrose e infiltrado inflamatório constituído por macrófagos e linfócitos. Na mucosa do cólon maior e ceco havia hiperplasia das células caliciformes com acentuada deposição de muco nas criptas e entre as vilosidades intestinais e moderada hiperplasia das células epiteliais, principalmente no Eqüino 2. O diagnóstico morfológico em todos os casos foi de colite e tiflite granulomatosa crônica multifocal acentuada associada a larvas de pequenos estrôngilos.

\section{DISCUSSÃO}

Os dados epidemiológicos, clínicos e os achados patológicos são idênticos aos descritos por outros autores para os casos de enterite associada a ciatostomíneos (Giles et al. 1985, Mair 1994, Reilly et al. 1993, Jasko \& Roth 1984 , AFIP 2000). Os cinco casos de enterite por ciatostomíneos totalizaram $6,3 \%$ das doenças do sistema digestivo de eqüinos examinados durante os 40 anos abrangidos pelo estudo. Todos os casos foram diagnosticados a partir de 1999. Alguns autores relacionam o aumento da incidência desse parasita e do número de casos de enterite associada a ciatostomíneos à (1) resistência dos pequenos estrôngilos à maioria dos anti-helmínticos usados atualmente, (2) maior quantidade de informações e o reconhecimento do parasita e das lesões provocadas por ele e (3) diminuição do parasitismo por grandes estrôngilos, principalmente Strongylus vulgaris, os quais mascaravam os efeitos patogênicos da infecção por pequenos estrôngilos (Lyons et al. 2000).

Dos cinco eqüinos afetados, quatro tinham menos de dois anos e um tinha 18 anos. A grande maioria dos casos descritos na literatura ocorreu em eqüinos com menos de 3 anos (Harmon et al. 1986, Schild et al. 1989, Reilly et al. 1993, Mair 1994). A infestação por ciatostomíneos em eqüinos jovens é, usualmente, maior do que em eqüinos adultos, o que pode indicar o desenvolvimento de certo grau de imunidade pelo hospedeiro e explicar a maior freqüência de casos de enterite associada a esses parasitas em eqüinos jovens (Lyons et al. 2000). Porém, a condição clinica e os casos fatais associados à enterite por ciatostomíneos têm sido descritos em eqüinos adultos (Giles et al. 1985).

Dos cinco casos descritos neste estudo, três ocorreram no inverno e dois em meados do outono. É descrito que condições favoráveis à ocorrência dessa doença em países de clima subtropical ocorrem no inverno (Courtney et al. 1999). Outros casos descritos no Rio Grande do Sul (Schild et al. 1989) ocorreram no mês de setembro, ou seja, final do inverno e início de primavera, o que, de certa forma, corrobora o possível caráter sazonal dessa condição em eqüinos do Estado. Há evidências que as $L_{3}$ ingeridas durante o outono permaneçam em hipobiose até o início da primavera. Durante esse período, pode ocorrer a emergência dessas larvas, possivelmente associada a fatores desencadeantes ainda pouco conhecidos (Urquhart et al. 1996).

Neste estudo, as espécies de ciatostomíneos não foram identificadas. A identificação dos ciatostomíneos nos estágios larvais é difícil e a classificação através dos ovos é impossível. A identificação desses parasitas, quando adultos, baseada na anatomia comparativa entre as espécies, é realizada por poucos pesquisadores (Lichtenfels et al. 2002). Esses fatores constituem os maiores desafios no entendimento e controle desses parasitas.

Dos cinco eqüinos deste estudo, três apresentavam diarréia, cujo curso clínico foi de 10 e 14 dias em dois casos. Apesar ser um sinal indicativo da doença associada à ciatostomíneos, a ocorrência de diarréia é variável. Em alguns casos, os sinais observados caracterizam-se apenas por emagrecimento progressivo, por vezes acompanhado de pirexia, edema subcutâneo e cólica, o que dificulta significativamente o diagnóstico clínico da doença. A diarréia e a perda de peso são decorrentes de função absortiva reduzida e a perda de proteínas é associada ao dano causado pela emergência das larvas na 
mucosa (Mair 1994). Neste estudo, não foram observados os sinais clínicos em dois eqüinos (Eqüinos 4 e 5), que foram encontrados mortos. Esses eqüinos eram criados extensivamente, o que impossibilitava a observação diária dos mesmos. Nestes casos o diagnóstico foi realizado pela observação das lesões intestinais macroscópicas e histológicas, associados a dados epidemiológicos e sinais clínicos em casos em que a doença foi clinicamente acompanhada. As lesões histológicas nos casos aqui descritos eram caracterizadas principalmente pela formação de granulomas parasitários na submucosa e mucosa do ceco e cólon maior, acompanhados de edema e infiltrado linfo-histioplasmocitário e eosinofílico moderado a acentuado na submucosa e mucosa. Conforme o estágio da inflamação, infiltrados focais ou difusos constituídos por macrófagos e neutrófilos ou granulomas parasitários podem ser predominantes na lesão. O infiltrado eosinofílico focal, edema e ruptura da muscular da mucosa são provocados pela emergência de larvas, seguida pela infiltração de neutrófilos e macrófagos. A quantidade de eosinófilos pode variar nas áreas afetadas. Também podem ser observados focos de células inflamatórias mononucleares na mucosa, como lesões residuais da emergência de larvas (AFIP 2000). Alguns autores (Reilly et al. 1993) mencionam que apenas a presença de numerosos cistos parasitários na mucosa do cólon maior e ceco, possam causar diarréia em eqüinos.

Os principais diagnósticos diferenciais clínicos para casos de diarréia em eqüinos incluem salmonelose, erliquiose monocítica eqüina, diarréia associada à administração de antibióticos (clostridioses intestinais), enterite por Rhodococcus equi, enterite associada à ciatostomíneos, enterite granulomatosa, neoplasias intestinais, peritonites, hepatopatias, intoxicação por arsênico, (Reilly et al. 1993, Brown et al., 2007). Nos casos aqui descritos, o diagnóstico de enterite granulomatosa por ciastotomíneos baseou-se na severidade dos achados macroscópicos e histopatológicos associada a numerosas larvas e adultos de ciatostomíneos no ceco e cólon maior.

\section{REFERÊNCIAS}

AFIP 2000. 28th Wednesday Slide Conference, Armed Forces Institute of Pathology, Maio 10, Case 1 (AFIP 2694912), enviado pela JustusLiebig-Universität Giessen, Alemanha. http://vp4.afip.org/wsc/wsc99/ 99wsc28. Acesso em 15.11.2008.

Brown C.C., Baker D.C. \& Barker I.K. 2007. Alimentary system, p.1296. In: Maxie M.G. (Ed.), Jubb, Kennedy and Palmer's Pathology of Domestic Animals. Vol. 2. 5th ed. Elsevier Saunders, Philadelphia. $771 \mathrm{p}$.

Courtney C.H. 1999. Seasonal transmission of equine cyathostomes in warm climates. Vet. Parasitol. 85:173-180.

Gardiner C.H. \& Poynton S.L. 2006. An Atlas of Metazoan Parasites in Animal Tissues. Armed Forces Institute of Pathology, Washington, DC. $64 p$.

Giles C.J., Urquhart K.A. \& Longstaffe J.A. 1985. Larval cyathostomiasis (immature trichonema-induced enteropathy): A report of 15 clinical cases. Eq. Vet. J. 17:196-201.

Harmon B.G., Ruoff W.W. \& Huey R. 1986. Cyathostome colitis and typhlitis in a filly. Compend. Contin. Vet. Education 8:S301-S306.

Jasko D.J. \& Roth L. 1985. Granulomatous colitis associated with small strongyle larvae in a horse. J. Am. Vet. Med. Assoc. 185:553-554.

Lichtenfels J.R., Gibbons L.M. \& Krecek R.C. 2002. Recommended terminology and advances in the systematics of the Cyathostominea (Nematoda: Strongyloidea) of horses. Vet. Parasitol. 107:337-342.

Lyons E.T., Drudge J.H. \& Tolliver S.C. 2000. Larval Cyathostomiasis. Vet. Clin. North Am. Equine Practice 16:501-513.

Love S., Murphy D. \& Mellor D. 1999. Pathogenicity of cyathostome infection. Vet. Parasitol. 85:113-122.

Mair T.S. 1994. Outbreak of larval cyathostomiasis among a group of yearling and two-year-old horses. Vet. Rec. 135:598-600.

Rech R.R., Oliveira F.N., Raffi M.B. \& Barros C.S.L. 2003. Diarréia associada à ciatostomíase em eqüino. 11ํㅡㄹ Enave, Botucatu, SP, p.133. (Resumo)

Reilly G.A.C., Cassidy J.P. \& Taylor S.M. 1993. Two fatal cases of diarrhea in horses associated with larvae of the small strongyles. Vet. Rec. 132:267-268.

Schild A.L., Riet-Correa F. Méndez M.C., Ferreira J.L.M. \& Brod C.S. 1989. Infecção por formas larvárias de Cyathostoma (Trichonema) em eqüinos. Boletim do Laboratório Regional de Diagnóstico no.10, Doenças diagnosticadas no ano 1988. Pelotas, p.17-20.

Urquhart G.M., Armour J., Duncan J.L., Dunn A.M. \& Jennings F.W. 1996. Parasitologia Veterinária. Guanabara Koogan, Rio de janeiro. 306p. 